\title{
Factors Affecting on the Price of Gold on Global Markets and Its Impact on the Price of Gold in Iran Market (Incorporation of Dynamic System Pattern and Econometric)
}

\author{
Nemat Falihy Pirbasti ${ }^{1} \&$ Mehdi Tajeddini ${ }^{2}$ \\ ${ }^{1}$ Faculty member of Islamic Azad University of Tehran-center branch \\ ${ }^{2}$ Master of economy of Islamic Azad University \\ Correspondence: Nemat Falihy Pirbasti, Faculty member of Islamic Azad University of Tehran-center branch). \\ E-mail:nfalihi@gmail.com/m.tajedini@cbi.ir
}

Received: January 20, 2016

Accepted: February 10, 2016

Online Published: February 25, 2016

doi:10.5539/mas.v10n3p124

URL: http://dx.doi.org/10.5539/mas.v10n3p124

\begin{abstract}
The financial crisis of 2008 caused that the gold price forecasting to be more important than was in the past. The mentioned importance is not just to earn more profits from gold speculative, but is because of the role that gold plays in the economic thermometer.

In this paper, has tried to using the corporation of dynamic system patterns and econometric to be discussed a wide range of variables affecting the price of gold and in addition to analyzing the global gold price, study it's impact on the gold price in Iran market. It seems that in Iran the exchange rate plays an important role in this regard. Also using dynamic simulation for a ten years period, means from 2015 to 2025 has forecasted the price of gold on global markets and Iran market. The results indicate a gradual decline in the gold price. The reality testing of model has examined by scenario plan of stopping the federal's expansionary policies that the results indicate the validity of the model.
\end{abstract}

Keywords: gold price forecast, dynamical systems, exchange rates and the financial crisis of 2008

\section{Introduction}

Gold is one of the basic assets that is in the portfolio of countries and even individual investment portfolio. Therefor the people may invest part of their liquidity in gold. In an economic downturn people tend going to the keeping gold and it can have different effects on macro-economy of countries. If the people's money spend on gold maintenance, the investment will decline, which leading to deeper economic downturn. In an economic downturn people tend more towards gold as a safe asset and according to the limitation of liquidity, certainly are reduced the amount of bank deposits significantly Which would affect the balance sheets of banks and thus their reserves in the central bank.

Currency stability requires a stable price trend for gold. If the gold price to rise, the currency price will also increase and vice versa. Also the speculation on futures gold shares severely affect the financial markets. So it will be very important to identify the factors affecting on it.

What we said was a summarized expressing of the increasing role of gold in the world's commercial equations. The aim of this study is to investigate the factors affecting the price of gold in global markets and the subsequent is discussed the effect of global gold price on the domestic gold price.

In this study, mainly will be considered the role of US money supply on the global price of gold. Which effects will have the US dollar and its volume on the future price of gold? How will be the gold relationship with macroeconomic variables such as economic growth, inflation and unemployment rate?

\section{Research History}

In Iran has not been done the study about the gold price predicting using dynamical systems, but in external research can be pointed out to Wi-pi and Harotai (2012) researches that after designing an analytical model for predicting the gold price in addition to considering the quantitative factors such as inflation rate, exchange rates, oil prices and interest rates propose qualitative factors such as political turmoil and financial crisis in the format 
of a dynamic model and prove that predicting the gold prices without considering qualitative factors cannot be a correct forecast. In this research, were studied the 2010 earthquake in Chile which led to the destruction two oil refineries and it predicts the gold prices to rise 4 to 5 percent by this event . Hiung Kim (2011) believes that the willingness of central banks to increase their gold reserves caused to profit-orientated investors to this market while buying gold by central banks may be have several reasons.

Fan and Kelchy (2010) in their study reached to a close relationship between the price of gold, the real interest rate and exchange rate. The most important result of their research was offering an idea against to common idea about the relationship between inflation and gold. In this study, doesn't introduce the gold as a safe bankroll facing inflation, but also due to the inherent fluctuations in gold prices is not as reliable at all. They know the gold as a foreign exchange that its value is a reflection of the dollar value and Federal Reserve monetary policy. However, that Adrenji (2003) believes the gold price has a positive relationship with expected inflation and by using it, can predict the gold price, but the price of gold has no specific relationship with uncompromised inflation. However, the general belief is based on the gold price has a direct and positive correlation with inflation in its general meaning. Because of this belief is that gold remembered as a safe guard against inflation.

Topco(2010), were examined the relationship between gold prices and the index of industrial production of Dove- Jones, America dollar exchange rate, oil prices, America's inflation rate, money supply and interest rates between time period of 1995 to 2009. Results indicated a positive relationship between gold output and oil prices, inflation rate, interest rates and the Dow-Jones Industrial Index and the negative relationship between gold revenue with liquidity.

\section{Theoretical Fundamental}

The price of gold is the theoretical resultant of four market forces. These four market that their dynamics relationship is shown in Figure 1 include money market, capital market, labor market and unorganized financial market.

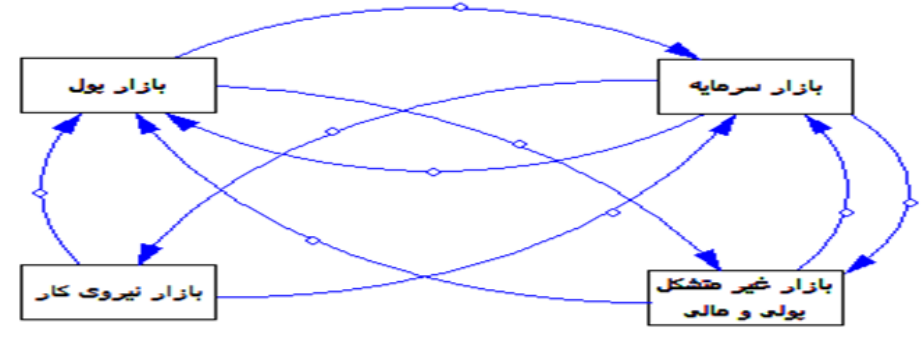

Figure 1. Main graph system pattern

Money market is with low risk of non-payment property, and high liquidity and nominal value. This market includes gold, exchange, oil and so on. It has Interaction with the capital market and non-organized financial market and is affected by labor market. Capital markets, is including the stock market. This market interact the money market and non-organized financial market and labor markets. The unemployment rate are discussed in the labor market, and finally is the non-organized financial market that cause price gap and is an unofficial market that in crisis times due to increasing demand, of speculation, activated and has a remarkable role in the Iran market.

The price of gold in general, is obtained of the impact of supply and demand of gold functions. But due to the specific sensitivity of gold, the situation is governed it that in terms forecast period is debatable.in better word the price of gold, unlike a lot of goods, sometimes "has a different process in the short term than the long term. On the other hand if forecast the price of gold in two levels of global and internal, also will add series of limitations and variables. In the meantime we have not to ignore the role of qualitative variables. In this article have selected the variables according to the relation of quartet markets, and then formulated proportionate to available theories and to estimate the coefficients are used the minimum squares method by eweuze software.

\section{The Global Trends and Domestic Price of Gold}

Figure 2 show changes of global price of an ounce of gold in the last thirty years. Gold price had the greatest volatility between 2008 and 2012. This volatility that always tends to increase is a sign of the global financial crisis. In other words, if consider the price of gold as an indicator of economic thermometer, it was possible to predict the financial crisis of 2008 during the 2000 to 2008. On the other hand should be mentioned the end of 
2012. In this period the price of gold, which was started grow upside from 12 years ago, with the arrival to the year of 2013 which was descending $r$ which represents exit from the crisis.

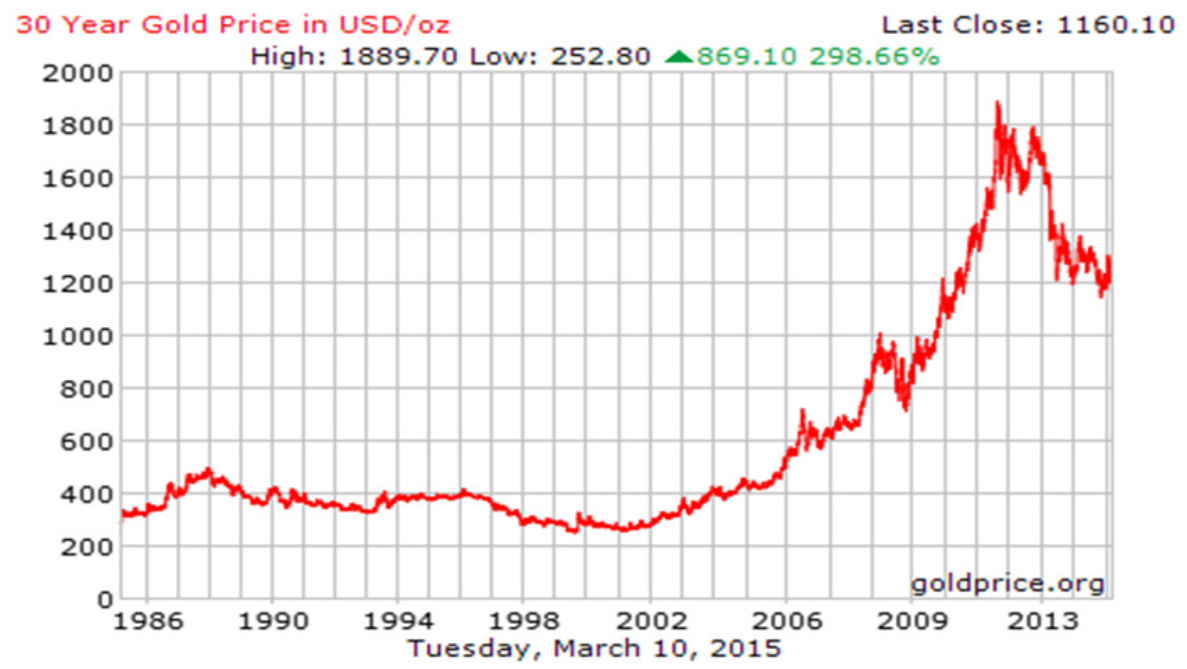

Figure 2.

The main reason for Iran and the global price of gold differences is the exchange rate. Exchange rate in this field is described regarding to the role of central bank in the formation of rational expectations. by studding the monetary policy used by Iran in the past years and compare it with what happens actually, it can be said that the central banks relying on the concept of rational expectations is trying to direct the economy.

According to Thomas Sargent opinion, the concept of rational expectations undermines the idea that policymakers can stimulate the economy by confusing the public in ways that systematically be wrong in their expectations. Robert Lucas showed that if expectations be rational, the government will not be able to use errors related to forecasting as reliable and predictable type, because errors by rational expectations predictors, are not inherently predictable. This Lucas idea led to what the economists call it as the story of affectability of policies, led. If people have rational expectations, the policies that try to force to move out the economy by inducing false expectations on people, only cause more disorder in economy and generally will not be able to improve the performance of economy.

This applies to discussion of coins pricing of by the Central Bank. Thus, in any policy that is applied to affect macroeconomic variables by monetary policy authorities should note that according to the theory of rational expectations, there is no possibility for misleading the economic agents for a long time and they can destroy the expected effect of the policy has been based on their ignorance by understanding and forecasting the economic environment.

The relation of this discussion with coin market is that the main reason for the formation of speculative bubbles in the coin market is the exchange market. In fact, the reason that central bank has repeatedly assured the community that will control the exchange market but has happened the against, is an example of misuse of the bank from the logic of rational expectations. Because in addition to the fundamental factors of the exchange market that assume the real dollar exchange rate than the Rial much higher than the current rate proportion to the outside world due to years of high inflation, is hidden in hypothesis of rational expectations and the issue of guidelines of Sargent and not affecting the policies.

Central Bank of Iran in appearance is respected to the official exchange rate but in action and in the calculation the coin price is respected to the exchange market rate. This factor causes the formation of coin bubbles. Which is shown in Figure 3.

\section{Introduction of Causal -Loop Chart of Iran Gold and Global Gold}

These charts meanwhile expression the causal relationships between two or more variables, specify their influence direction. The effect on the desired variables can be performed directly or indirectly via intermediary variables. In this paper, first proposed the ring related to adjustment the gap of gold price in Iran and the world gold price separately, then overall loop simulation is put forward. Figure 4 shows the gap between the prices of 
gold in Iran and the world. In viewpoint of causal-loop diagrams can be stated that to some extent has reduced the demand for gold that has a great gap with the world price, the existence gap increases, so create a reverse relationship, which cause to create a negative ring .

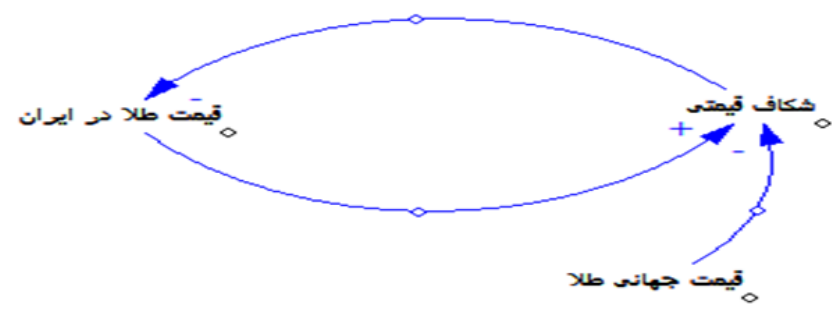

Figure 3. The main graph of system pattern

But what is the coin bubble? To explain this issue first it is necessary to explain the formula of calculating the coin price. Coin price changes strongly is comes from global gold price changes and dollar price in the domestic market.

Theoretical price of coin is calculated using the following formula.

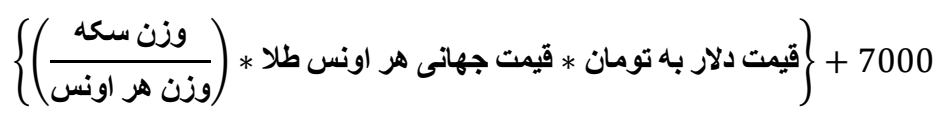

To use this formula should attention the following contexts:

The global gold prices will be announced by cutie of 24 or $999 \%$ to American Dollar. Also each ounce is equal to 31.103431 gram. Coins cutie in is $18 \%$ or $9 \%$ in Iran .cost of coin minting is considered about 7000 USD. Weight of (Bahar Azadi) coin is 8.133 grams, half coin and a quarter coin are respectively 4.0665 gram and 2.03325 gram.

According to the above formula it is clear that by coin price, vary with the global price of gold and dollar price changes. For example, if the global price of gold be $1700 \$$ and dollar exchange rate be 1350 Tomans, with the above formula, the price of the coin is about 548000 Tomans.

But usually the coins in the market transact at a price different from the theoretical price, that its reason is the anticipation of traders from global gold price and the dollar exchange rate in the domestic market. If predict the global price of gold rising, the coin prices will traded slightly higher. For example, if predict the investment in global gold price and the dollar exchange rate at 6 months later, respectively, 2,000 \$ and 1,400 \$, the theoretical coin price in the next 6 months is estimated equal to 666000 dollars and if expect the annual return of $24 \%$ (6 months $12 \%$ ) by decreasing the 666000 Toman with annual rate of $24 \%$ annual for six month, it reach to 598000 Toman that this number show the inherent coin price.

To calculate the intrinsic cost of the coin there is the following formula:

No maybe the coin be traded on the market for 620,000 USD. So for the coins calculated 3 prices theoretical price 548000, inherent price 598000 and the market price 620000 .

It can be seen that people introduce the difference in market price and the theoretical price as coin bubble while this is not true. In fact, surplus of market price and intrinsic value of the coins have to consider as a bubble. In this case the difference between the market price and theoretical price to be introduced as a bubble, the bubble must considered 72,000 Tomans for coin but the real bubble is 22000 Tomans, it means that the coins in the market are traded 22,000 Tomans higher than their intrinsic value traded. Although the calculation of the coin bubble is depend on expected benefit rate of investor and his expectations and estimates of the future.

\section{The Estimating of the Model}

Increasing the oil prices, cause to increasing global inflation and, in these circumstances, investors want to converse money to something that have most resistant against inflation, gold is one of the best choices and thus the gold price will increase. On the other hand, gold and oil have the same common affecting factors that because the prices of these two commodities be aligned. For example, regional tensions in the Middle East cause to increase the oil and gold prices. The impact of oil prices on the gold cause that the oil indirectly effect on many commodities, stocks and currencies of different countries. 
Gold has an undeniable historical role in attracting people to protect their capital. In this study, the consumer price index, is considered influencing by factors such as liquidity, interest rates, economic growth and the oil price.

Uncertainty that caused by the war in the oil-exporting countries has so extent range, that in recent years, the discussion of be or not to be is proposed. The kind that people in these countries do not have confidence even in the political future of their countries. Definitely, these conditions will affect their economic behavior and on the other hand the financial crisis has changed not only people behavior but also the behavior of central banks, for example central banks that usually were the seller of gold were turned to the main buyers of gold during this period.

LOG $($ Gold Price $)=\alpha 0+\alpha 1$ cpi $+\alpha 2$ GR $-\alpha 3$ usd $x+\alpha 4$ un $+\alpha 5$ spdr $-\alpha 6$ sp $+\alpha 7$ R $+\alpha 8$ DUM $11+\alpha 9$ DUM $12+$ ut

LOG $($ cpi $)=\alpha 0+\alpha 1$ LOG $($ Oil Price $)+\alpha 2$ LOG $($ gdp $)+\alpha 3$ LOG $(M 2)+\alpha 4 R+\alpha 5$ DUM11+ut

Minus sign of USD factor coefficient indicates correlation between the unemployment rate and US dollar value. There is also evident positive relationship between inflation and unemployment rate.

Remarkable point is the rejection of Philips theory. Philips curve in fact indicates the existence and stability of an inverse relationship between two important economic problems of unemployment and inflation in America and other advanced countries of. Accordingly, we can write:

$\mathrm{U}=-\alpha 0-\alpha 1$ LOG (usdx) $+\alpha 2$ LOG (cpi) $+\alpha 3$ DUM11 +ut

Also according to the findings can be said that US dollar index and GDP have a positive relationship with New York stock indexes:

$\mathrm{SP}=\alpha 0+\alpha 1$ usd $-\alpha 2 \mathrm{u}+\alpha 3 \mathrm{gdp}+\alpha 4 \mathrm{DUM} 11+\mathrm{ut}$

On the other hand a point out that US is the studied population for predicting the gold price. The reason of this selection returns to the role of America in the global economy. Looking at this position in the collection of statistics on the international community clearly indicate economic significance of this country.

According to what was said, variables include: Gold Price (global price of gold), CPI (consumer price index), GR (global demand for gold saving by central banks, usdi (USD index), U (unemployment rate of us) and R (interest rate of us) that the accumulation model and its flow for global gold price is as follows. dynamical system model presented in this paper that is based on the theory of dynamical system balance ,represents quantitative and qualitative factors affecting the price of gold that by running the model can be found that what factors affect the price of gold and how affect and how is the gold price feedback on each of these variables. required coefficients to systematically display of gold price extracted using 2-4 relation by Eviews software.

LOG $($ Gold Price $)=3.6+.018 \mathrm{cpi}+0.002 \mathrm{GR}-0.013 \mathrm{usdx}+2.8 \mathrm{UN}+0.004 \mathrm{spdr}-0.00053 \mathrm{SP}+0.018 \mathrm{R}$

$\mathrm{LOG}(\mathrm{CPI})=6.1+0.02 \mathrm{LOG}(\mathrm{OIL}$ PRICE $)-0.04 \mathrm{LOG}(\mathrm{gdp})+0.05 \mathrm{LOG}(\mathrm{M} 2)+0.002 \mathrm{R}$

$\mathrm{U}=-6.4-5.8 \mathrm{LOG}(\mathrm{usdx})+7.6 \mathrm{LOG}(\mathrm{cpi})$

$\mathrm{SP}=37.5+3.18 \mathrm{usdx}-72.6 \mathrm{u}+0.1 \mathrm{gdp}$

The gold price has negative and significant relationship whit variables of USD and New York stock index. There is a significant negative correlation between gold price and the USD index that been violated in some cases. Also, every time the price of gold rising, the stock indices have been deteriorating around the world. The results have been match with previous studies.

The price of gold has a positive and significant relationship with the Consumer Price Index (inflation), the demand for storage of gold and the unemployment rate. These relations are largely based on scientific and historical issues. The significant positive relationship between gold prices and inflation return to the historic role of gold in disguise for the people's wealth, it means that the people to keep their money against the inflation change their wealth to the gold.

Positive relationship between gold prices and the demand for storage of gold by central banks around the world, in addition to the law of supply and demand, is clearly demonstrated during the 2008 financial crisis. During this period, the central banks tried to favorable use of these conditions by increasing their gold reserves. The interesting point in this period was that theories governed on macro and micro economy were too close to each other such that central banks that due to their legal situation and policy makers role, free of these issues, were acted as a profit economic fair in the market.

The significant positive correlation between gold prices and America's unemployment rate is reasonable because 
in addition to historical observations can be said that any improvement in the economy of America is indicator to stop the economic stimulus plan of this country that increased investors' concerns about the future of the gold market. It means that reducing the unemployment rate is a positive sign for the economy and decreases the community's concern and cause to increasing USD Index, which has a significant negative correlation with the gold price. The unemployment rate of US has the largest share in estimating the price of gold. The relationship between interest rates and gold prices was meaningless and positive; the interest rate has negative and meaningful correlation with gold price in a binary relationship but in combination of variables is positive. In some studies it is proven otherwise. Also should be mentioned the determining factor of represent 96 percent that indicates the high explanatory power of the model. Watson camera test of 1.81 indicates the lack of communication of the wastes in different time periods or lack of correlation between them.

\section{Pattern Analysis}

Original art of modeling is introducing the feedback processes that accompanying with state structures determines the time delays and non-linear dynamicity of a system. All the dynamicity of the system is obtained from causal-loop diagrams interactions that include positive and negative loops.

\subsection{Positive Loop(Self-Reinforcing)}

If by increasing a variable, increase the other variable or move in the same direction, this will lead to strengthen the system. Figure 5 is shown a positive ring

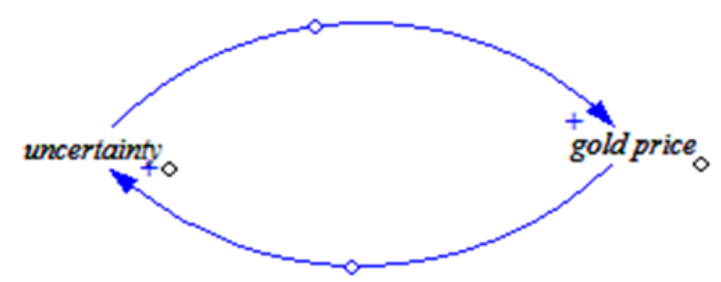

Figure 5 .

In this loop uncertainty cause to increases the price of gold ring and also increasing the gold prices also will cause uncertainty. Phenomenon such as war, financial crisis and ... make uncertainty in the economy. Economic uncertainty refers to a situation where people do not know the value of their wealth in the future thus it's going to protect their wealth with a variety of investment portfolios. In fact, the positive loop represents exponential growth of discussed variable over time.

\subsection{Negative Loop (Self-Correcting)}

If by increase a variable, the other variable decreases or move in the against direction, this increasing has had a neutralizing role and is against the change and cause to neutralize the changes .in fact the negative loop is activated to restore the lost balance. In other words, the negative loop causes to control the exponential growth which created by the positive loop. In Figure 6, is displayed a negative loop in relation to the gold price:

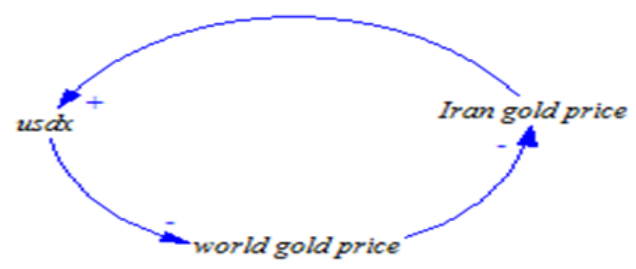

Figure 6. Negative loop of gold market

It can be seen that increasing the USD value because of an inverse historical relationship between the global gold and the dollar, cause to reducing the global gold price. However, one of the factors that directly affect the price of gold in Iran is the global Gold. Therefore, reducing the global gold price cause to reduction Iran gold price.

Also, if asset the relationship between gold and the dollar during the last 30 years with the regression line, we will realize that there is always a direct relationship between the dollar and gold of Iran. Every time the price of 
gold is expensive relatively the dollar has increased too. This means that every time people have some gold and the price rises, they transacted it by dollar. Thus the gold and USD price will increase. Accordingly the rise in the dollar after rising gold price is not surprising.

In other words, people to more benefit by increasing cost of gold, tend to deal with dollar. In recent years the growth of dollar doesn't have any factor but gold price increasing. Naturally, by reduction in the price of gold on the condition of other factors stability, falls the rates of dollar. Considering that in a country like Iran, only $10 \%$ of foreign exchange transactions is in government exclusive and 90 percent of transactions are done in free market ,it is normal that gold prices have a direct impact on the dollar price .

\subsection{Analysis of the Global Gold Prices in Format of Dynamic Systems is Shown in Figure 7}

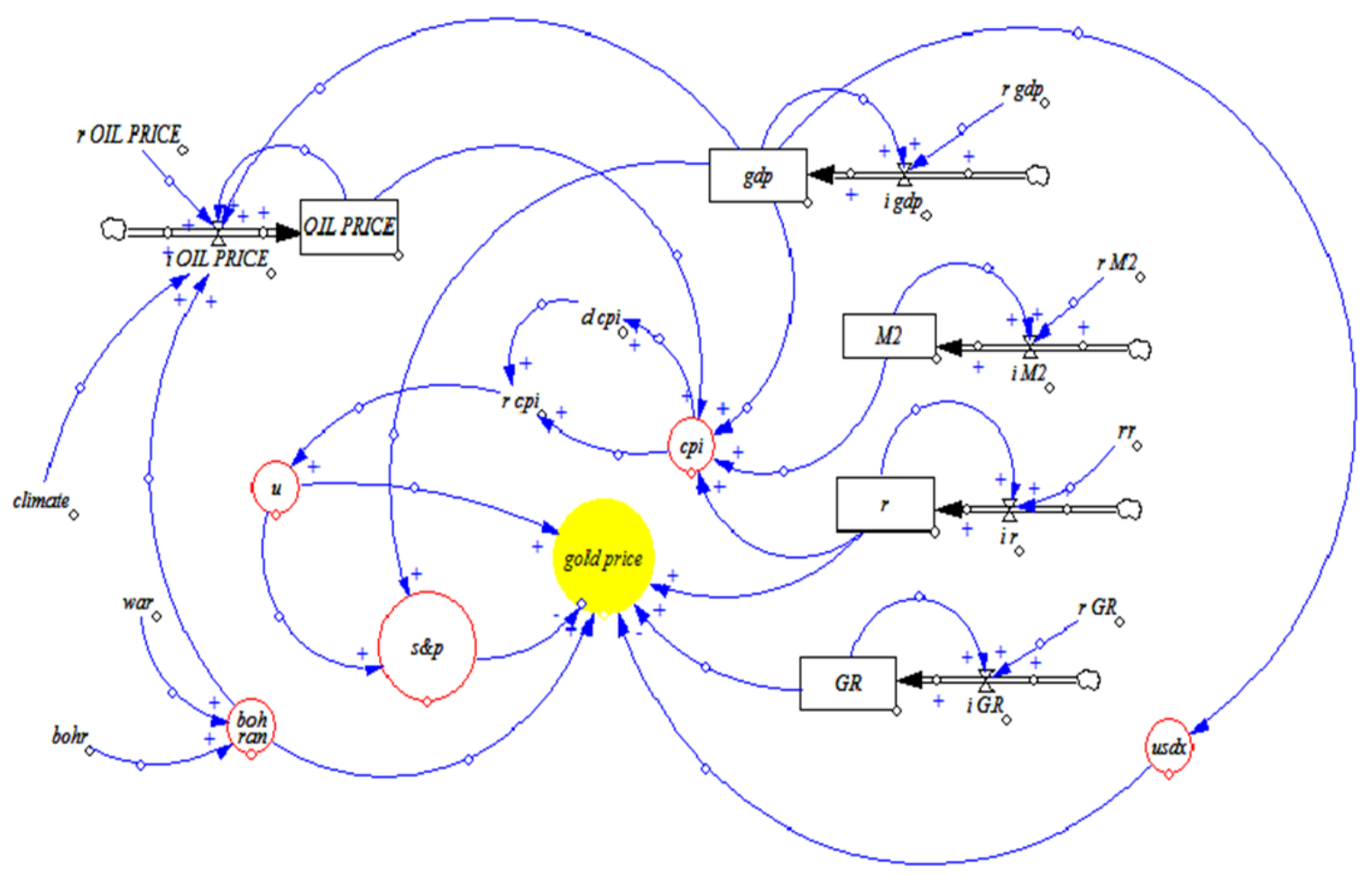

Figure 7.

\subsection{Stopping the Tensional Monetary Policies Scenario by the Federal Reserve}

In the aftermath of the crisis the most important parameter affecting the gold price is the situation of Federal's bond-buying program that is the modern form of printing money that will follow objectives such as stimulating demand, restore prosperity to America's economy and reducing the unemployment in the country. The Federal Reserve has implemented three quantitative easing programs.

In the framework of this program, the Federal Reserve bought risky assets of banks and meanwhile reducing the risk of their bankruptcy, raises the bank lending power, and along with low interest rates, expects raises the demand for more loans and investment. In addition to this policy, an important event is taking place and it is the devaluation of the dollar price that cause to replacement the purchases rather than saving that means wheel of America's economy will rotate more that is in recovering period after the recession. The dollar's value decline along increasing the demand for goods, create inflation power, which is a sign of the coming boom. The continuation of this program with respect to its effects certainly is raising power of gold price. Whenever the Federal Reserve tone about the economy is positive and give signals to reduce exchange paper buying and even give signals to higher interest rates, then the price of gold will decline.

The tonology of the Federal Reserve is sometimes not an easy task; meanwhile, the sensitivity on signals of the Federal Reserve is not unreasonable. Repeatedly simple words of Federal Reserve chairman become reality, and for this, the market is sensitive to the word spoken by the president and his reports.

The unemployment rate of 6.5 percent and inflation rate of 2 percent are announced of the Federal Reserve goals 
to stop buying bonds. Now the labor market is improving and the unemployment rate is at 7.3 percent, and there is hope of its recovery in the coming months, but inflation rate is not very promising. Consumer price index (CPI) has had increasing procedure in the year ended to October 2013, and is equal to one percent. No improvement in inflation in conditions that a strong expansionary policy is applying, indicate the high power of price deflation forces that is frustrating. Certainly, low inflation rate if they stop buying bonds, will go lower. Given that coverage against the risks of inflation in particular is one of the gold functions, thus the absence of inflationary force along with the Fed's tensional expansionary policy stop, will create much more increasing downward force on the gold price. So with this scenario that the Federal reserve are attempting to stop the tensional expansionary policies ,the gold price in 2025 should be close to 1,000 dollars per ounce and due to affectability of gold in the domestic market has declining procedure . Figure 8 shows this issue:

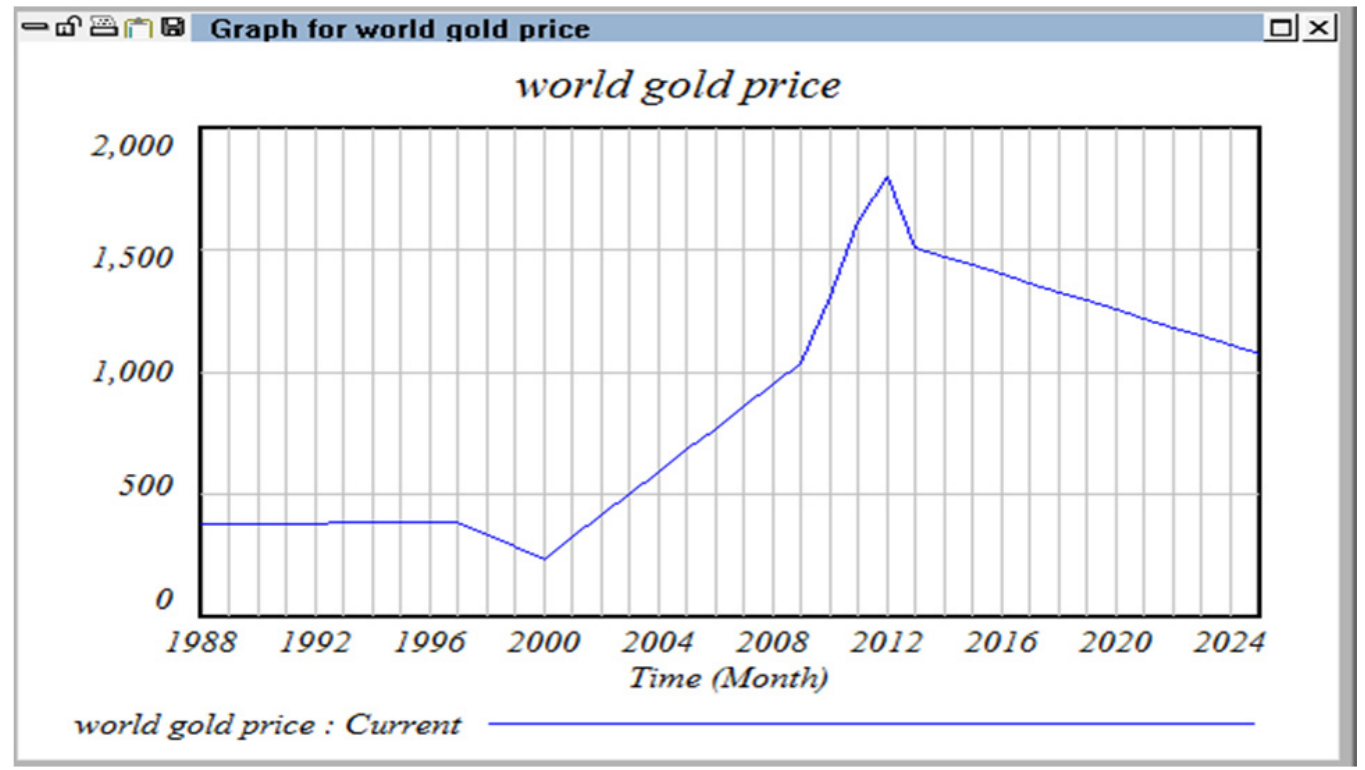

Figure 8 . The gold price and Scenario of tensional monetary expansionary policy stop by the Federal Reserve

\subsection{Findings and Recommendations}

For some reasons, such as elimination the effects of the global financial crisis in 2008, improving the performance of stocks and bonds market, inflation containment, real interest rates and stop the implementation of tensional monetary expansionary by the Federal Reserve ,the prediction of declining in the world price of gold seems to be true .

The recent financial crisis by increasing the financial instruments has caused a widespread shift of wealth between the various social classes. Outside the scope of finance behavior, many ordinary people who have little savings will enter to this speculation because attracting market by market operators, and falls and fail against the massive wealth of gold and money holders. Growth of wealthy people chain, at the peak of the crisis in the world and the spread of poverty and unemployment in Europe and America community level prove it.

On the other hand the independent central bank from the government as country monetary policer plays an important role in stabilizing the market economy. Double behavior of the central bank to the exchange rate, is realized by the economic agents and not only will not be managed the exchange rate, but also have reverse result due to rational deduction of agents, rises their attempt to save the currency to the hope of future price increasing and price controls policy. Also the exchange policy, essentially are considered "demand section policies and using it to control the supply section is a great wrong, while there is very reasonable policy in the supply section.

\section{References}

Albin, S. (1997). Building a system dynamics model part 1: Conceptualization. MIT System Dynamics in Education Project, MIT, Cambridge, MA, Technical Report.

Bantz, S. G., \& Deaton, M. L. (2006). Understanding U.S. biodiesel industry growth using system dynamics. IEEE Systems and Information Engineering Design Symposium, Charlottesville, VA, 156-161. 
Davis, J. H., \& Aliaga-Diaz, R.. A. (2008). Oil, the economy, and the stock market. Retrieved from http://ssrn.com/abstract=1136524 or http://dx.doi.org/10.2139/ssrn.1136524

Feldstein, M. (1981). The effects of inflation on the prices of land and gold. J. Public Econ., 309-317.

Forrester, J. W., \& Martin, L. A. (1997). Beginner exercises. MIT System Dynamics in Education Project, MIT, Cambridge, MA, Technical Report, 1997.

Pirog, R. (2006). Oil industry profit review 2005. CRS, Washington DC, Order Code RL33373.

Sjaastad, L. A., \& Scacciavillani, F. (1996). The price of gold and the exchange rate. J Int Money Financ, 15(6), 879-897.

System Dynamics Group (1998). Guided study program in system dynamics,” MIT, Cambridge, MA, Technical Report.

Vannasetta, P., \& Tharmmaphornphilas, W. (2011). Oil price using system dynamics," in Proceedings of the 2nd International Conference on Business and Economics, Lhasa, Tibet.

Wolstenholme, E. F. (1999). Qualitative v. quantitative modelling: The evolving balance. J. Oper. Res. Soc., 50(4), 422-428.

\section{Copyrights}

Copyright for this article is retained by the author(s), with first publication rights granted to the journal.

This is an open-access article distributed under the terms and conditions of the Creative Commons Attribution license (http://creativecommons.org/licenses/by/3.0/). 